\title{
Schizophrenia: Recognition and Management in the ED
}

Aryeh Dienstag, MD

\section{In this review, the author describes the symptoms and proper diagnosis of schizophrenia, focusing on the appropriate management and treatment options for patients in the ED setting.}

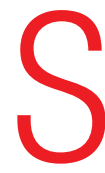

chizophrenia has a heterogeneous presentation including both positive and negative symptoms. It is a relatively common disorder, affecting $0.7 \%$ of the world's population. ${ }^{12}$ Schizophrenia is defined by abnormalities in two or more of five domains: ${ }^{3}$

- Delusions,

- Hallucinations,

- Disorganized thinking/speech (eg, frequent derailment or incoherence),

- Grossly disorganized or abnormal motor behavior (including catatonia), or

- Negative symptoms (ie, diminished emotional expression or avolition).

Schizophrenia is defined as having two or more of the above domains. Each must present for a significant portion of time during a 1-month period (or less if successfully treated). At least one of these must be delusions, hallucinations, or disorganized speech. This must cause dysfunction in a major area, such as work, interpersonal relations, or selfcare. Signs of the disturbance persist for at least 6 months. If mood symptoms exist, they may only be present for a minority of the total duration of symptoms. Symptoms are not attributable to the physiological effects of a substance (eg, a drug of abuse, a medication) or another medical condition. ${ }^{3}$

If symptoms are present for less than 1 month, then the diagnosis is brief psychotic disorder. If symptoms are present between 1 month and 6 months, then the diagnosis is schizophreniform disorder. If a patient has only delusions but does not hallucinate; possesses disorganized speech, grossly disorganized, or catatonic behavior; and negative symptoms, then the diagnosis is delusional disorder.

The exact pathophysiology of schizophrenia is not known at this time. However, it is theorized to be a mix of biological and environmental factors leading to dysfunction of the neurotransmitters dopamine and glutamate, as well as structural changes to the brain. ${ }^{2}$

Dr Dienstag is an attending physician, department of psychiatry, Hadassah Medical Center, Jerusalem, Israel.

Author's Disclosure Statement: The author reports no actual or potential conflict of interest in relation to this article.

Acknowledgements: The author would like to thank Dr Any Jagoda, Dr Leslie Zun, and Dr Silvana Riggio for help with this article.

DOI: 10.12788/emed.2018.0106 


\section{Methods}

There is an abundance of research on schizophrenia in the psychiatry literature; however, much of this deals with chronic management in patients with established diagnoses, thus this may be hard to translate into the realities of emergency practice. At the same time, although schizophrenia is discussed in the emergency medicine literature, most ED-based research is performed in patients with undifferentiated agitation and not specifically on one diagnostic subset. Therefore, a narrative review was utilized in order to focus in on studies that are relevant to emergency practice.

A narrative literature search was performed utilizing PubMed, the Cochrane database, and American Psychiatric Association Practice Alerts for the past 3 years; bibliographies of major psychiatric textbooks; and reviews and clinical policies in the National Guidelines Clearinghouse.

\section{Epidemiology}

The lifetime prevalence of schizophrenia is approximately $0.3 \%$ to $0.7 \% .^{2}$ In addition, schizophrenia is a frequently deadly disease as one meta-analysis found lifetime suicide to be $4.9 \%$, which is far higher than the average risk in the United States, ${ }^{4}$ which is approximately $0.5 \%$. From 1992 to 2000 there has been a 15\% increase in ED visits for psychiatric problems. ${ }^{5}$ Patients with schizophrenia have been found to be significantly more likely to be "high utilizers" of ED services in comparison to those with other psychiatric diagnoses. ${ }^{6}$

The increase in psychiatric presentations to EDs is coupled with a lack of psychiatrists in many areas of the United States. The American Hospital Association has reported that $40 \%$ of American hospitals have difficulty maintaining adequate psychiatric coverage to meet patient demand in the ED, forcing many emergency medicine physicians to act as a primary psychiatrist. ${ }^{7}$

\section{Differential Diagnosis}

The characteristic symptoms of schizophrenia can be present in many other illnesses; therefore, the emergency clinician must be able to distinguish schizophrenia from other illnesses presenting with a psychotic component. Furthermore, schizophrenia is a diagnosis of exclusion as the diagnosis can only be made after all medical etiologies of the symptoms have been excluded.

Items on the differential include delirium, a substance induced psychosis, ${ }^{8}$ which can be caused by both substance intoxication and substance withdrawal; as well as psychosis caused by another medical condition. ${ }^{8}$ It should be stressed that a prior diagnosis of schizophrenia does not rule out a medical etiology of a patient's current psychotic episode; therefore, a thorough history and examination is fundamental, even in patients with a known history of psychiatric illness. Moreover, many patients with schizophrenia present with a medical chief complaint, despite being symptomatic regarding their schizophrenia. In the latter case, providers must be vigilant regarding any medical comorbidities, particularly when patients are actively psychotic.

Finally, within the psychiatric disorders there are multiple disorders other than schizophrenia that may have psychotic features, including depression with psychotic features, bipolar disorder with psychotic features, and the other schizophrenia spectrum disorders; including brief psychotic disorder, schizophreniform disorder, schizoaffective disorder, and delusional disorder. 


\section{Emergency Department Evaluation}

The process of evaluation of psychiatric patients who present to the ED should be directed towards a determination as to whether hospitalization is warranted, treatment of underlying medical condition is needed, or psychiatric care is indicated. New onset of psychiatric illness will commonly call for extensive evaluation, whereas patients with chronic schizophrenia may not need testing but may need psychiatric hospitalization. ${ }^{9}$ Additionally, emergency clinicians are frequently requested to preform "medical clearance" by their psychiatrist colleagues, before a patient can be transferred to a psychiatry department or psychiatric hospital. However, this is a poor term and a better nomenclature would be "assess for medical stability." Emergency clinicians are, in essence, being asked whether the patient is medically stable enough for transfer to a unit or hospital where there is little or no medical support. Prior to transfer to a psychiatric unit, a patient's non-psychiatric medical conditions should be stable enough for outpatient management.

\section{Interacting with Patients Suffering from Psychosis}

Although providers should not pretend to interact in the patient's reality, they should express understanding in what the patient thinks or feels and kindly direct them back to the current situation. ${ }^{10}$ It is important for providers in the acute setting to be non-judgmental about reasons for relapse (in particular non-adherence to medication or substance misuse). ${ }^{10}$ Challenging the patient, while at times useful, is best done once the patient is stabilized and in a controlled environment.

\section{History}

The history should focus on age of onset; prior history of psychiatric symptoms; history of medical illness and use or abuse of illicit substances, as well as medications; the stability of psychotic symptoms; and if hallucinations are present, whether they are auditory or visual in nature. ${ }^{10}$ Table 1 highlights the differences between a patient presenting with a psychiatric complaint and the psychotic symptoms secondary to a medical illness. Table 2 provides salient differences between the examination of a patient with psychosis due to a psychiatric illness or another medical condition. Additionally, Table 3 lists various features, which differentiates schizophrenia from other psychiatric illnesses.

Additionally, patients with schizophrenia can become just as physically ill as anyone else; however, they may have difficulty expressing their specific physical complaints. Furthermore, patients with schizophrenia have a pronounced incidence of early death compared to the general population. ${ }^{11}$ Therefore, performing a simple physical examination and paying attention to vital signs can rule out or detect a great deal of organic pathology. ${ }^{12}$

Once a diagnosis of schizophrenia is made, the next priority is to determine whether the patient is a threat to themselves or others and whether this threat is imminent or not. Statements of suicidal or homicidal ideation, intent, and/or plan are the basic methods of screening for danger. However, physicians also need to screen for command auditory hallucinations, prior history of suicidal behavior, and violence. Finally, even in a patient with previously diagnosed schizophrenia, screening must also be done for substance intoxication and withdrawal.

\section{Diagnostic Studies}

The indications for diagnostic studies are influenced by whether the presentation is experiencing first break psychoses vs a presentation in a patient with known schizophre- 
Table 1. Comparison of Historical Features Distinguishing Organic Causes of Psychiatric Complaints from True Psychological or Functional Disease

\begin{tabular}{ll}
\hline Non-Psychiatric Medical Illness & Psychiatric Illness \\
\hline $\begin{array}{l}\text { Age of onset }>30 \text { years, which is rare onset of acute psychiatric ill- } \\
\text { ness }\end{array}$ & Age of onset $<30$ years \\
\hline Sudden onset of psychiatric symptoms & Gradual onset of psychiatric symptoms \\
\hline No previous diagnosis of a psychiatric illness & Previous diagnosis of a psychiatric illness \\
\hline No family history of psychiatric illness & $\begin{array}{l}\text { Significant family history of psychiatric illness } \\
\text { (in particular first-degree relatives) }\end{array}$ \\
\hline History of organic illness & No history of organic illness \\
\hline History of substance or medication use/abuse & No history of substance or medication use/abuse \\
\hline $\begin{array}{l}\text { New medications (including over-the-counter and herbal } \\
\text { medications) }\end{array}$ & No new medications \\
\hline Tactile or visual hallucinations & Auditory hallucinations \\
\hline $\begin{array}{l}\text { Symptoms not corresponding to a specific psychiatric diagnosis } \\
\text { Adapted with permission from Emerg Med Clin North Am }{ }^{21} \text { and Eur Rev Med Pharmacol Sci. }{ }^{75}\end{array}$
\end{tabular}

Table 2. Comparison of Examination Findings Distinguishing Medical Causes of Psychiatric Complaints from Psychological Disease

\begin{tabular}{ll}
\hline Non-Psychiatric Medical Illness & Psychiatric Illness \\
\hline Abnormal vital signs & Normal vital signs \\
\hline Confusion, disorientation to time and place & Alert and oriented x 3 \\
\hline Fluctuating level of consciousness & Stable level of consciousness \\
\hline Sudden fluctuations of psychiatric symptoms & Stable or slowly (hours to days) fluctuating psychiatric symptoms \\
\hline Focal neurological findings & Normal neurological examination \\
\hline Evidence of trauma (eg, raccoon eyes, battle sign) & No evidence of trauma \\
\hline Coexisting signs of a specific organic illness & No signs of organic illness \\
\hline $\begin{array}{l}\text { Abnormal dermatologic manifestations } \\
\text { (eg, rashes, purpura, jaundice, uremic, frost) }\end{array}$ & No skin changes \\
\hline Poor response to psychiatric treatment & Robust response to psychiatric treatment \\
\hline Adap &
\end{tabular}

Adapted with permission from Emerg Med Clin North Am ${ }^{21}$ and Eur Rev Med Pharmacol Sci. ${ }^{75}$

nia. In the former case there is a greater need for laboratory and other diagnostic tests. In the latter case minimal testing will likely be necessary. Patients with new onset psychiatric symptoms generally need extensive laboratory and radiographic evaluations, including a computed tomography scan of the head. ${ }^{9}$ 
Table 3. Elements of the Examination, Which Differentiate Schizophrenia from Other Psychiatric IIInesses

\begin{tabular}{lll}
\hline Illness & Element of Examination & Finding \\
\hline Major Depressive Disorder & History & Psychosis only occurs during mood episodes \\
\hline Bipolar Disorder & History & Psychosis only occurs during mood episodes \\
\hline Dementia & Cognitive examination & $\begin{array}{l}\text { Patient presents with abnormal cognitive } \\
\text { finding on one of the major domains (memory, } \\
\text { concentration, orientation, etc.) }\end{array}$ \\
\hline Delirium & History and cognitive examination & $\begin{array}{l}\text { Sudden onset } \\
\text { Fluctuating symptoms } \\
\end{array}$ \\
& Orientation or cognitive dysfunction \\
\hline Substance-Induced Psychosis & History & $\begin{array}{l}\text { Recent ingestion of recreational or prescribed } \\
\text { substance }\end{array}$ \\
\hline
\end{tabular}

For patients who have an established schizophrenia, extensive evidence supports that there is no need for testing and indeed more often results in false positives, ${ }^{11,13}$ and selective testing based on findings in the history and physical examination is the correct strategy. ${ }^{11}$

Complicating the decision to obtain laboratory tests is the fact that many psychiatric facilities rely on referring hospitals to perform baseline testing, as they do not have the resources to perform the tests or to manage any identified abnormalities. Therefore, some tests are needed prior to transfer. In addition, at times, baseline laboratory tests are needed prior to starting antipsychotics. ${ }^{14}$

Additionally, some tests are unlikely to affect immediate disposition or treatment but may be useful to psychiatrists for long-term treatment planning. ${ }^{15}$ A common disagreement between psychiatrists and emergency providers is the urine toxicology screen or a blood alcohol level. Urine toxicology or a blood alcohol level does not usually affect initial treatment and disposition in the ED. ${ }^{11,16}$ However, it may be invalid if collected subsequent to a transfer from the ED, and can determine whether a patient requires specific substance use disorder treatment or not. ${ }^{16-18}$ Therefore, many psychiatric providers will request a urine toxicology screening or a blood alcohol level before accepting a transfer. Please note, urine toxicology screens only identify a small number of toxic ingestions. Therefore, a negative screen does not eliminate drug abuse or overdose.

Finally, in the case that a diagnostic examination is being done to satisfy a requirement for an institution to accept a patient or to assist in long-term treatment planning, disposition should not be delayed in order to wait for the result to return. ${ }^{11}$

\section{Treatment}

Unfortunately, no level I or II studies have been found that examine the indications for treatment of the psychiatric patient in the ED. ${ }^{9}$ Additionally, in the ED, there is an illdefined difference between the use of psychotropic medications as an intervention after patient assessment and plan of care, and the use of these medications to control behavior without an assessment and treatment plan. ${ }^{9}$ Therefore, many treatment recommendations have been made based on studies in other settings.

The first line treatment for a patient with schizophrenia is monotherapy with an antipsychotic agent other than clozapine. ${ }^{19-21}$ (Clozapine is not used as a first line agent due 
to its high side effect burden and the testing necessary before starting.) This is supported by multiple randomized controlled trials and is the standard of care. ${ }^{22-24}$ The response rates in treatment with antipsychotics in studies specifically designed to examine treatment of first-episode schizophrenia are high, ranging from $46 \%$ to $96 \%{ }^{23}$ Therefore, the emergency medicine provider can confidently reassure patients and families that antipsychotic medications are effective in treating schizophrenia. Loading doses of antipsychotics should not be used. ${ }^{19}$

Although there are only small and inconsistent differences between different antipsychotics, other than clozapine, with respect to efficacy, there are large differences in adverse effect profiles. ${ }^{25-30}$ Therefore, the choice of antipsychotic medication is generally made based on previous response to individual antipsychotic medications and relative side effects. ${ }^{31}$

If extrapyramidal symptoms, including tardive dyskinesia, are of particular concern to a patient, then second generation or low potency first generation antipsychotics should be used..$^{25,32}$ If a patient complains of previous problems with sedation, then haloperidol or aripiprazole should be preferred. ${ }^{25}$ Haloperidol, aripiprazole, or amisulpride should be considered for patients who are particularly concerned about weight gain, or who may be at the greatest risk of weight gain. ${ }^{25}$

If there is no response to medication after 4 weeks, ${ }^{32}$ despite dose optimization, a change in antipsychotic should be considered..$^{33,34}$ Where there is partial response, the patient should be re-assessed after 8 weeks unless there are significant adverse effects. ${ }^{14,19,20,34} \mathrm{~A}$ combination of different antipsychotic medications should not be used, except during transitional periods when patients are being switched from one antipsychotic to another, or when used for clozapine augmentation. ${ }^{14}$

After an acute episode has passed, providers can consider offering depot/long-acting injectable antipsychotic medication to people with schizophrenia who would prefer such treatment; as long acting injectable antipsychotics have been shown to reduce medication non-adherence. ${ }^{35,36}$ Long-acting depot antipsychotics should not be used for acute episodes because it may take 3 to 6 months for the medications to reach a stable state. ${ }^{14}$

Once a patient achieves a remission of their symptoms, patients are recommended to stay on their antipsychotic medication for at least 2 years since their last acute exacerbation. ${ }^{14,34}$ For maintenance therapy, the antipsychotic dose should be reduced gradually to the lowest possible effective dose, which should not be lower than half of the effective dose during the acute phase. ${ }^{37}$

Clozapine should be offered to people with schizophrenia whose illness has not responded adequately to treatment with adequate doses of at least two different antipsychotic drugs. ${ }^{38-41}$ There is no indication to using dual antipsychotic agents on patients with schizophrenia prior to starting a clozapine trial. ${ }^{42,43}$

\section{Non-Pharmacological Intervention}

There is strong evidence that people diagnosed with schizophrenia benefit from psychosocial treatments in addition to pharmacological treatment. Multiple randomized controlled studies, as well as national guidelines, have demonstrated cognitive behavioral therapy and family therapy to be effective for the treatment of schizophrenia. ${ }^{44-51}$ Particular focuses of therapy include communication skills, problem solving, psychoeducation, and assisting with family conflict, ${ }^{18,19}$ which are feasible in an emergency setting. ${ }^{52}$

Recent studies have shown promise using a "crisis intervention" approach as an alternative option to the hospital or emergency medical services systems. Treatment usually involves a combination of medication as well as counseling (practical help with living 
skills and support for close family members). After the crisis has been stabilized, sufferers are carefully introduced to other models of care more suited for the chronic phases of psychiatric illnesses. ${ }^{53}$ This is particularly important as psychosocial instability, such as changes in the psychosocial environment (ie, a primary caretaker going on vacation, or a patient being distanced from their family or support environment) have been associated with relapse. ${ }^{19}$

\section{Acute Agitation}

The vast majority of patients suffering from mental illness, including schizophrenia, are not violent and only a small proportion of the violence in our society can be attributed to persons who are mentally ill..$^{54}$ Furthermore, people with psychiatric disabilities are far more likely to be victims than perpetrators of violent crime. ${ }^{55}$ However, schizophrenia and related disorders are associated with substantially increased rates of violence and violent offences compared to those who did not, independent of substance use. ${ }^{56,57}$ Furthermore, the majority of acute hospital assaults occur in the ED. ${ }^{58}$

Two emergency medicine evidence-based guidelines state a benzodiazepine (lorazepam or midazolam) or a conventional antipsychotic (droperidol or haloperidol) should be used as monotherapy for the treatment of acute undifferentiated agitation in the ED. ${ }^{12,59}$ However, in cases of patients with a diagnosis or suspicion of schizophrenia, an antipsychotic should be used in order to start a "disease modifying agent" earlier in the course of treatment. ${ }^{20,59,60}$ Where possible, the same antipsychotic should be used as monotherapy for treatment of both acute agitation and standing antipsychotic medication..$^{13}$ The choice of medication for the treatment of acute agitation should be based on patient preference, past experience of antipsychotic treatment, the adverse effect profile, and concurrent medical history. ${ }^{19,58}$ This is supported by a case controlled study, which showed patients' subjective experiences in the acute phase of treatment affected their long-term adherence to medication. ${ }^{61}$

Haloperidol is the most commonly used medication for agitation in patients with schizophrenia. ${ }^{59,62}$ When haloperidol is used to treat acute violence, it is almost always used in combination with a benzodiazepine unless medically compromised. ${ }^{62,63}$ Intramuscular olanzapine has been shown to be effective in managing acute aggression or agitation in patients with schizophrenia, especially where it is necessary to avoid some of the older treatments. Olanzapine causes fewer movement disorders than halopridol. ${ }^{64}$ Chlorpromazine is available in both per os and intramuscular formulations. However, chlorpromazine is associated with more side effects than other antipsychotics, including a higher incidence of prolonged QT and Torsades. ${ }^{65}$ However, where choices are limited, chlorpromazine may be the only treatment available for acute agitation. If used, the close monitoring of blood pressure is indicated ${ }^{65}$ Inhaled loxapine received US Food and Drug Administration approval for treatment of acute agitation in $2012 .{ }^{66}$ This is a useful option for an agitated patient who is calm enough to receive an inhaler, but is unable to take medication per os.

Restrictive intervention (restraints or seclusion) should only be used if de-escalation and other preventive strategies, including medication as needed, have failed and there is potential for harm to the patient or other people if no action is taken. ${ }^{58}$

\section{Telepsychiatry Consultation}

Telepsychiatry is an approach, where by EDs that do not have access to psychiatrists can see patients in the ED itself, by forming a contract with either psychiatrists or companies to allow a psychiatrist at another location to perform an examination on a patient via vid- 
eo connection and advise the emergency room providers on treatment and intervention. There is very little data in the peer-reviewed literature on the use of telepsychiatry. The literature is limited to case reports, program descriptions, and randomized studies for reliability. ${ }^{67,68}$ One randomized controlled trial showed that a telepsychiatry evaluation had a reliable diagnosis and disposition when compared to a face-to-face assessment. ${ }^{69}$ One case control showed reduction in time-to-consult done in the ED, length of stay, and door-to-consult stay, once a telepsychiatry program was initiated. ${ }^{70} \mathrm{~A}$ large case control study showed that telepsychiatry recipients were more likely to receive 30-day followup, 90-day follow-up, and total inpatient length of stay, totaling both initial admission and subsequent admissions. ${ }^{71}$ Therefore, it is reasonable for EDs to take advantage of telepsychiatry services if no immediate psychiatrist coverage is available.

\section{Disposition}

The primary disposition question regarding a patient presenting with a psychiatric chief complaint to the ED, including schizophrenia, is whether they require a psychiatric admission or not. If a patient requires hospitalization but refuses, the emergency clinician must decide if the patient meets criteria for involuntarily hospitalization. If a patient does not require an inpatient admission or would benefit from an inpatient admission but does not meet criteria for civil commitment, then the next major question is what type of outpatient treatment is sufficient for this particular patient (Figure).

For a patient with schizophrenia to require inpatient psychiatric admission he must be either a danger to himself or others or has failed outpatient treatment. In addition, the patient must currently have undergone a clinical evaluation of any suspected medical illness, and any medical problems the patient is experiencing must be sufficiently stable to allow safe transport and treatment at a psychiatric hospital unit. ${ }^{9}$ If a patient's medical condition is not sufficiently stable for either transport or hospitalization at a psychiatric hospital but the patient still requires inpatient psychiatric treatment, the patient should be hospitalized on a standard medical ward and receive psychiatric care on that unit.

Patients with mental illness pose an additional challenge, in that their illness often time interferes with their judgment about whether they require treatment. Because of this possible lack of capacity and the potential danger of a patient with mental illness to self or others, most jurisdictions have a legal code that allows for involuntary hospitalization of the mentally ill. However, which patients qualify for involuntary hospitalizations vary by jurisdiction. Case law criteria for emergencies range from a risk of "imminent" harm to self or others to a deterioration in the patient's mental condition if treatment is halted. ${ }^{72}$ Providers are recommended to familiarize themselves with laws regarding inpatient civil commitment in their particular jurisdiction.

When a patient is being discharged from the ED, either because they do not require a psychiatric inpatient admission or because they don't meet criteria for involuntary commitment, there are various outpatient dispositions available. Any patient with a diagnosis of schizophrenia should have outpatient follow-up with a mental health provider upon discharge from the ED.

For patients who have a failed community treatment in the past, who do not have a significant support network, or whose disease is too severe for a regular outpatient clinic to handle would be better suited for a disposition to a transitional program over a standard outpatient appointment; such as partial hospitalization programs, intensive outpatient programs, and community mental health treatment teams (CMHT). Assertive community treatment (ACT) teams are a form of CMHT comprised of several disciplines, including nurses, occupational therapists, psychiatrists, psychologists, and social work- 


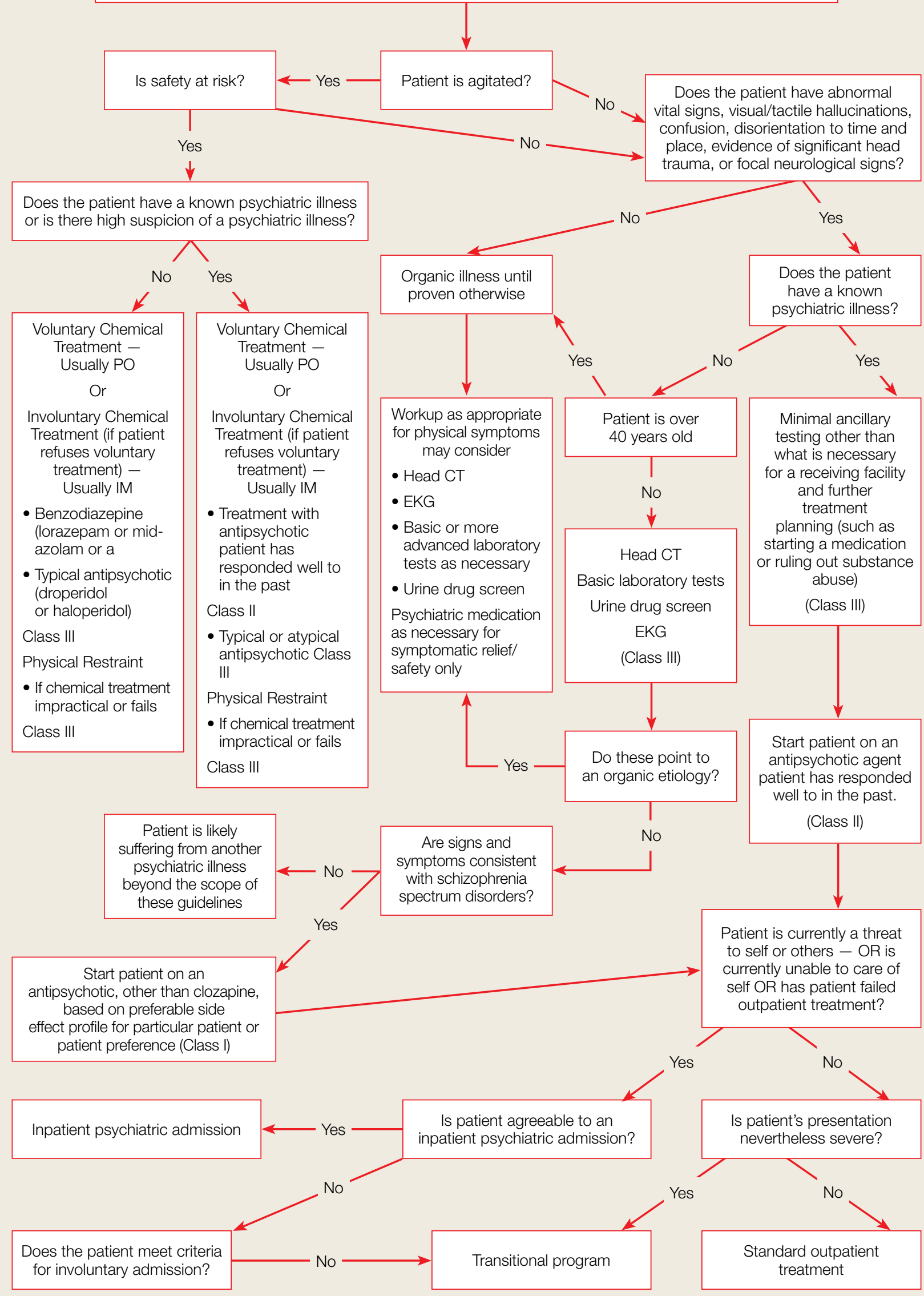


ers. ${ }^{73} \mathrm{~A}$ large prospective cohort study found homeless patients to have made gains in multiple spheres of mental health while enrolled in ACT programs, and these benefits were retained after discharge from the ACT program. ${ }^{74}$

\section{Conclusion}

Schizophrenia is characterized primarily by delusions, hallucinations, and disorganized thinking. Emergency medicine providers are frequently at the front lines of diagnosing, initiating treatment, and managing relapses for these individuals. As schizophrenia is an exclusion, the primary task of an emergency physician is to rule out all "organic", for lack of a better term, causes of the psychosis or disordered thinking before making a definitive diagnosis of schizophrenia. As many EDs do not have sufficient psychiatry support and many patients with schizophrenia are using the ED as their location for primary mental health, many emergency physicians are finding themselves acting as the main providers for these individuals. The primary treatment for patients with schizophrenia remains monotherapy with antipsychotic medication. Although the highest-level disposition for a patient with schizophrenia remains the inpatient psychiatry department, there are many transitional dispositions that can bridge the gap between a discharge to standard community care and an inpatient admission.

\section{References}

1. MacDonald AW, Schulz SC: What we know: findings that every theory of schizophrenia should explain. Schizophr Bull. 2009;35(3):493-508. doi:10.1093/schbul/sbp017.

2. McGrath J, Saha S, Chant D, Welham J. Schizophrenia: a concise overview of incidence, prevalence, and mortality. Epidemiol Rev. 2008;30:67-76. doi:10.1093/epirev/mxn001.

3. American Psychiatric Association. Diagnostic and Statistical Manual of Mental Disorders: DSM-5. 5th ed. Washington, DC: American Psychiatric Association; 2013.

4. Palmer BA, Pankratz VS, Bostwick JM. The lifetime risk of suicide in schizophrenia: a reexamination. Arch Gen Psychiatry. 2005;62(3):247-253.

5. American College of Emergency Physicians. Psychiatric and substance abuse survey 2008. http://newsroom.acep. org/download/ACEP\%2BPsychiatric\%2Band\%2BSubstance\%2BAbuse\%2BSurvey\%2B-\%2BApril\%2B2008.pdf. Accessed October 7, 2018.

6. Pasic J, Russo J, Roy-Byrne P. High utilizers of psychiatric emergency services. Psychiatr Serv. 2005;56(6):678-684

7. American Hospital Association. AHA annual survery database. http://www.ahadata.com/aha-annual-survey-database-asdb/. Accessed October 7, 2018.

8. Testa A, Giannuzzi R, Daini S, Bernardini L, Petrongolo L, Gentiloni Silveri N. Psychiatric emergencies (part III): psychiatric symptoms resulting from organic diseases. Eur Rev Med Pharmacol Sci. 2013;17 Suppl 1:86-99.

9. Zun LS. Evidence-based evaluation of psychiatric patient. J Emerg Med. 2005;28(3):277-283.

10. Bryan CA, Mistovich JJ, Krost WS, Limmer DD. In two minds? EMS care of the schizophrenic patient. Recognizing the signs and symptoms of schizophrenia is key to prehospital care. EMS Mag. 2009;38(12):63-71.

11. Lukens TW, Wolf SJ, Edlow JA, et al; American College of Emergency Physicians Clinical Policies Subcommittee (Writing Committee) on Critical Issues in the Diagnosis and Management of the Adult Psychiatric Patient in the Emergency Department. Clinical policy: critical issues in the diagnosis and management of the adult psychiatric patient in the emergency department. Ann Emerg Med. 2006;47(1):79-99.

12. Crump C, Winkleby MA, Sundquist K, Sundquist J. Comorbidities and mortality in persons with schizophrenia: a Swedish national cohort study. Am J Psychiatry. 2013;170(3):324-33. doi:10.1176/appi.ajp.2012.12050599.

13. Kroll DS, Smallwood J, Chang G. Drug screens for psychiatric patients in the emergency department: evaluation and recommendations. Psychosomatics. 2013;54(1):60-66. doi:10.1016/j.psym.2012.08.007.

14. Verma S, Chan LL, Chee KS, et al; MOH Clinical Practice Guidelines Workgroup on Schizophrenia. Ministry of Health clinical practice guidelines: schizophrenia. Singapore Med J. 2011;52(7):521-525.

15. Fochtman LJ. Psychiatric perspectives on medical screening of psychiatric patients. Acad Emerg Med. 2002;9(9):963-964

16. Tijdink JK, van den Heuvel J, Vasbinder EC, can de Ven PM, Honig A. Does on-site urine toxicology screening have an added diagnostic value in psychiatric referrals in an emergency setting? Gen Hosp Psychiatry. 2011;33(6):626630. doi:10.1016/j.genhosppsych.2011.07.008.

17. Janiak BD, Atteberry S. Medical clearance of the psychiatric patient in the emergency department. J Emerg Med. 2012;43(5):866-870. doi:10.1016/j.jemermed.2009.10.026.

18. Lehman AF, Lieberman JA, Dixon LB, et al; American Psychiatric Association; Steering Committee on Practice Guidelines. Practice guideline for the treatment of patients with schizophrenia, second edition. Am J Psychiatry. 2004;161(2 Suppl):1-56.

19. National Institute for Health and Care Excellence. Psychosis and schizophrenia in adults: prevention and management. https://www.nice.org.uk/guidance/cg178. Published February 2014. Accessed September 25, 2018.

20. Scottish Intercollegiate Guidelines Network. SIGN 131: Management of schizophrenia. https://www.sign.ac.uk/ assets/sign131.pdf. Published March 2013. Accessed September 25, 2018. 15.

21. Tucci V, Siever K, Matorin A, Moukaddam N. Down the rabbit hole: emergency department medical clearance of 
patients with psychiatric or behavioral emergencies. Emerg Med Clin North Am. 2015;33(4):721-737. doi:10.1016/j. emc.2015.07.002.

22. Tandon R, Belmaker RH, Gattaz WF, et al; Section of Pharmacopsychiatry, World Psychiatric Association. World Psychiatric Association Pharmacopsychiatry Section statement on comparative effectiveness of antipsychotics in the treatment of schizophrenia. Schizophr Res. 2008;100(1-3):20-38. doi:10.1016/j.schres.2007.11.033.

23. Leucht S, Arbter D, Engel RR, Kissling W, Davis JM. How effective are second-generation antipsychotic drugs? A meta-analysis of placebo-controlled trials. Mol Psychiatry. 2009;14(4):429-447. doi:10.1038/sj.mp.4002136.

24. Robinson DG, Woerner MG, Delman HM, Kane JM. Pharmacological treatments for first-episode schizophrenia. Schizophr Bull. 2005;31(3):705-722.

25. Leucht S, Corves C, Arbter D, Engel RR, Li C, Davis JM. Second-generation versus first-generation antipsychotic drugs for schizophrenia: a meta-analysis. Lancet. 2009;373(9657):31-41. doi:10.1016/S0140-6736(08)61764-X.

26. Komossa K, Rummel-Kluge C, Hunger H, et al. Olanzapine versus other atypical antipsychotics for schizophrenia. Cochrane Database Syst Rev. 2010;3:CD006654. doi:10.1002/14651858.CD006654.pub2.

27. Komossa K, Rummel-Kluge C, Hunger H, et al. Amisulpride versus other atypical antipsychotics for schizophrenia. Cochrane Database Syst Rev. 2010;1:CD006624. doi:10.1002/14651858.CD006624.pub2.

28. Komossa K, Rummel-Kluge C, Hunger H, et al. Ziprasidone versus other atypical antipsychotics for schizophrenia. Cochrane Database Syst Rev. 2009;4:CD006627. doi:10.1002/14651858.CD006627.pub2.

29. Komossa K, Rummel-Kluge C, Schmid F, et al. Aripiprazole versus other atypical antipsychotics for schizophrenia. Cochrane Database Syst Rev. 2009;4:CD006569. doi:10.1002/14651858.CD006569.pub3.

30. Komossa K, Rummel-Kluge C, Schmid F, et al. Quetiapine versus other atypical antipsychotics for schizophrenia. Cochrane Database Syst Rev. 2010;1:CD006625. doi:10.1002/14651858.CD006625.pub2.

31. Crossley NA, Constante M, McGuire P, Power P. Efficacy of atypical v. typical antipsychotics in the treatment of early psychosis: meta-analysis. Br J Psychiatry. 2010;196(6):434-439. doi:10.1192/bjp.bp.109.066217.

32. Correll CU, Schenk EM. Tardive dyskinesia and new antipsychotics. Curr Opin Psychiatry. 2008;21(2):151-156. doi:10.1097/YCO.0b013e3282f53132.

33. Emsley R, Rabinowitz J, Medori R. Time course for antipsychotic treatment response in first-episode schizophrenia. Am J Psychiatry. 2006;163(4):743-745.

34. Barnes TR; Schizophrenia Consensus Group of British Association for Psychopharmacology. Evidence-based guidelines for the pharmacological treatment of schizophrenia: recommendations from the British Association for Psychopharmacology. J Psychopharmacol. 2011;25(5):567-620. doi:10.1177/0269881110391123.

35. MacEwan JP, Kamat SA, Duffy RA, et al. Hospital readmission rates among patients with schizophrenia treated with long-acting injectables or oral antipsychotics. Psychiatr Serv. 2016;67(11):1183-1188.

36. Patel MX, Taylor M, David AS. Antipsychotic long-acting injections: mind the gap. Br J Psychiatry. 2009;52:S1-S4. doi:10.1192/bjp.195.52.s1.

37. Uchida H, Suzuki T, Takeuchi H, Arenovich T, Mamo DC. Low dose vs standard dose of antipsychotics for relapse prevention in schizophrenia: meta-analysis. Schizophr Bull. 2011;37(4):788-799. doi:10.1093/schbul/sbp149.

38. Swartz MS, Stroup TS, McEvoy JP, et al. What CATIE found: results from the schizophrenia trial. Psychiatr Serv. 2008;59(5):500-506. doi:10.1176/ps.2008.59.5.500.

39. Jones PB, Barnes TR, Davies L, et al. Randomized controlled trial of the effect on Quality of Life of second- vs firstgeneration antipsychotic drugs in schizophrenia: Cost Utility of the Latest Antipsychotic Drugs in Schizophrenia Study (CUtLASS 1). Arch Gen Psychiatry. 2006;63(10):1079-1087.

40. Chakos M, Lieberman J, Hoffman E, Bradford D, Sheitman B. Effectiveness of second-generation antipsychotics in patients with treatment-resistant schizophrenia: a review and meta-analysis of randomized trials. Am J Psychiatry. 2001;158(4):518-526.

41. McEvoy JP, Lieberman JA, Stroup TS, et al; CATIE Investigators. Effectiveness of clozapine versus olanzapine, quetiapine, and risperidone in patients with chronic schizophrenia who did not respond to prior atypical antipsychotic treatment. Am J Psychiatry. 2006;163(4):600-610.

42. Centorrino F, Goren JL, Hennen J, Salvatore P, Kelleher JP, Baldessarini RJ. Multiple versus single antipsychotic agents for hospitalized psychiatric patients: case-control study of risks versus benefits. Am J Psychiatry. 2004;161(4):700-706.

43. Stahl SM, Grady MM. A critical review of atypical antipsychotic utilization: comparing monotherapy with polypharmacy and augmentation. Curr Med Chem. 2004;11(3):313-327.

44. Turkington D, Sensky T, Scott J, et al. A randomized controlled trial of cognitive-behavior therapy for persistent symptoms in schizophrenia: a five-year follow-up. Schizophr Res. 2008;98(1-3):1-7.

45. Malik N, Kingdon D, Pelton J, Mehta R, Turkington D. Effectiveness of brief cognitive-behavioral therapy for schizophrenia delivered by mental health nurses: relapse and recovery at 24 months. J Clin Psychiatry. 2009;70(2):201-207.

46. Haddock G, Barrowclough C, Shaw JJ, Dunn G, Novaco RW, Tarrier N. Cognitive-behavioural therapy v. social activity therapy for people with psychosis and a history of violence: randomised controlled trial. BrJ Psychiatry. 2009;194(2):152-157. doi:10.1192/bjp.bp.107.039859.

47. Lysaker PH, Davis LW, Bryson GJ, Bell MD. Effects of cognitive behavioral therapy on work outcomes in vocational rehabilitation for participants with schizophrenia spectrum disorders. Schizophr Res. 2009;107(2-3):186-191. doi:10.1016/j.schres.2008.10.018.

48. Grant PM, Huh GA, Perivoliotis D, Stolar NM, Beck AT. Randomized trial to evaluate the efficacy of cognitive therapy for low-functioning patients with schizophrenia. Arch Gen Psychiatry. 2012;69(2):121-127. doi:10.1001/ archgenpsychiatry.2011.129.

49. Girón M, Fernández-Yañez A, Mañá-Alvarenga S, Molina-Habas A, Nolasco A, Gómez-Beneyto M. Efficacy and effectiveness of individual family intervention on social and clinical functioning and family burden in severe schizophrenia: a 2-year randomized controlled study. Psychol Med. 2010;40(1):73-84. doi:10.1017/ S0033291709006126.

50. Bressi C, Manenti S, Frongia P, Porcellana M, Invernizzi G. Systemic family therapy in schizophrenia: a randomized clinical trial of effectiveness. Psychother Psychosom. 2008;77(1):43-49.

51. Chien WT, Lee IY. The schizophrenia care management program for family caregivers of Chinese patients with schizophrenia. Psychiatr Serv. 2010;61(3):317-320. doi:10.1176/ps.2010.61.3.317. 
52. Sneed J, Balestri M, Belfi BJ. The use of dialectical behavior therapy strategies in the psychiatric emergency room. Psychotherapy Theory, Research \& Practice. 2003;40(4):265-277.

53. Murphy SM, Irving CB, Adams CE, Wagar M. Crisis intervention for people with severe mental illnesses. Cochrane Database Syst Rev. 2015;12:CD001087. doi:10.1002/14651858.CD001087.pub5.

54. Mulvey EP. Assessing the evidence of a link between mental illness and violence. Hosp Community Psychiatry. 1994;45(7):663-668.

55. Hiroeh U, Appleby L, Mortensen PB, Dunn G. Death by homicide, suicide, and other unnatural causes in people with mental illness: a population-based study. Lancet. 2001;358(9299):2110-2112.

56. Van Dorn R, Volavka J, Johnson N. Mental disorder and violence: is there a relationship beyond substance use? Soc Psychiatry Psychiatr Epidemiol. 2012;47(3):487-503. doi:10.1007/s00127-011-0356-x.

57. Fazel S, Wolf A, Palm C, Lichtenstein P. Violent crime, suicide, and premature mortality in patients with schizophrenia and related disorders: a 38-year total population study in Sweden. Lancet Psychiatry. 2014;1(1):44-54.

58. National Institute for Health and Care Excellence. Violence and aggression: short-term management in mental health, health and community settings. https://www.nice.org.uk/guidance/ng10/chapter/About-this-guideline. Published May 2015. Accessed September 24, 2018.

59. Wilson MP, Pepper D, Currier GW, Holloman GH Jr, Feifel D. The psychopharmacology of agitation: consensus statement of the american association for emergency psychiatry project Beta psychopharmacology workgroup. West J Emerg Med. 2012;13(1):26-34. doi:10.5811/westjem.2011.9.6866.

60. Tiihonen J, Miitendorfer-Rutz E, Torniainen M, Alexanderson K, Tanskanen A. Mortality and cumulative exposure to antipsychotics, antidepressants, and benzodiazepines in patients with schizophrenia: an observational followup study. Am J Psychiatry. 2016;173(6):600-606. doi:10.1176/appi.ajp.2015.15050618.

61. Lambert M, Conus P, Eide P, et al. Impact of present and past antipsychotic side effects on attitude toward typical antipsychotic treatment and adherence. Eur Psychiatry. 2004;19(7):415-422.

62. Allen MH, Currier GW, Carpenter D, Ross RW, Doherty JP; Expert Consensus Panel for Behavioral Emergencies 2005. The expert consensus guideline series. Treatment of behavioral emergencies 2005. J Psychiatr Pract. 2005;11 Suppl 1:5-108.

63. Leucht S, Heres S, Kissling W, Davis JM. Evidence based pharmacotherapy of schizophrenia. Int J Neuropsychopharmacol. 2011;14(2):269-284. doi:10.1017/S1461145710001380.

64. Belgamwar RB, Fenton M. Olanzapine IM or velotab for acutely disturbed/agitated people with suspected serious mental illnesses. Cochrane Database Syst Rev. 2005;2:CD003729.

65. Ahmed U, Jones H, Adams CE. Chlorpromazine for psychosis induced aggression or agitation. Cochrane Database Syst Rev. 2010;4:CD007445. doi:10.1002/14651858.CD007445.pub2.

66. US Food and Drug Administration. Drug approval package. https://www.accessdata.fda.gov/drugsatfda_docs/ nda/2012/022549_adasuve_toc.cfm. Accessed September 28, 2018.

67. Salmoiraghi A, Hussain S. A systematic review of the use of telepsychiatry in acute settings. J Psychiatr Pract. 2015;21(5):389-393. doi:10.1097/PRA.0000000000000103.

68. Shore JH, Hilty DM, Yellowlees P. Emergency management guidelines for telepsychiatry. Gen Hosp Psychiatry. 2007;29(3):199-206.

69. Seidel RW, Kilqus MD. Agreement between telepsychiatry assessment and face-to-face assessment for emergency department psychiatry patients. J Telemed Telecare. 2014;20(2):59-62. doi:10.1177/1357633X13519902.

70. DeVido J, Glezer A, Branagan L, Lau A, Bourgeois JA. Telepsychiatry for inpatient consultations at a separate campus of an academic medical center. Telemed J E Health. 2016;22(7):572-576. doi:10.1089/tmj.2015.0125.

71. Narasimhan M, Druss BG, Hockenberry JM, et al. Impact of a telepsychiatry program at emergency departments statewide on the quality, utilization, and costs of mental health services. Psychiatr Serv. 2015;66(11):1167-1172. doi:10.1176/appi.ps.201400122.

72. Simon RI, Shuman DW. Clinical issues in psychiatry and the law. In: Hales RE, Yudofsky SC, Roberts LW, eds. The American Psychiatric Publishing Textbook of Psychiatry. 6th ed. Washington, DC: American Psychiatric Publishing; 2014:175-204.

73. Malone D, Newron-Howes G, Simmonds S, Marriot S, Tyrer P. Community mental health teams (CMHTs) for people with severe mental illnesses and disordered personality. Cochrane Database Syst Rev. 2007;3:CD000270.

74. Rosenheck RA, Dennis D. Time-limited assertive community treatment for homeless persons with severe mental illness. Arch Gen Psychiatry. 2001;58(11):1073-1080.

75. Testa A, Giannuzzi R, Sollazzo F, Petrongolo L, Bernardini L, Daini S. Psychiatric emergencies (part I): psychiatric disorders causing organic symptoms. Eur Rev Med Pharmacol Sci. 2013;17 Suppl 1:55-64. 